\title{
Teaching/learning \\ Architectural Design based on a Virtual \\ Learning Environment
}

Luisa Dalla Vecchia,

Adriane da Silva and Alice Pereira 


\section{Teaching/learning Architectural Design based on a Virtual Learning Environment}

Luisa Dalla Vecchia,Adriane da Silva and Alice Pereira

This paper describes an experiment in which a virtual learning environment was used in the context of an architectural design course. The objective was to evaluate the capability of the learning environment used to support the interactions needed, between teacher-student and between students, for the establishment of a process of discussion and development of architectural design. Some limitations were identified and also positive points, such as the possibility to register the whole design process. These registers allow the design teacher to evaluate his own teaching process and improve it and also the visualization of what kind of intervention the teacher makes and when, making it possible to identify the kind of design processes established by the student and the kind of structure of knowledge which is implicit in a process of teaching/learning architectural design according to the level of development of the design. 


\section{Introduction}

This research experiments the use of a virtual learning environment in a context of teaching/learning architectural design with the purpose of finding alternatives for the improvement of the didactic process in this context seeking ways to make the teaching/learning process more transparent.

As a starting point is the consideration made by Silva (1984)[I] that the design process mustn't be compared to a black box - a mechanism in which is impossible to see how it works, knowing only the income or the problem, and the outcome or answer - but to a transparent or glass box which is possible to observe how it works. This author points out that if the design is the rational effort to solve a certain problem it must imply some sort of organized knowledge.[I]

It is up to the educational institution to explicit this process. However, the way architectural design is taught, in the context analyzed, is very similar to that described by Schön (2000)[2] in which there is no effort to make the process explicit. This author describes the usual practice of teaching/learning architectural design as that in which each student must develop their own version of the design, keeping their results in preliminary sketches, studies and models. At the end of the semester there is a meeting in which the students present their designs to the teacher and in some cases a board of evaluating teachers. From time to time during the semester, a revision of the design is carried out with each one of the students who the teacher orients individually. This dynamic in architectural design courses treats the process as a black box. The students don't share the different methodologies adopted throughout the process, hardly discuss as a group the decisions made and don't explicit the references used in each moment for the conception of the design. All this could make each one of the processes, established by the students, richer, revealing the design process.

It is considered that even the designer has a lot of difficulty in describing the process in details. Rarely in the context of architectural design courses there is an effort to build discourses that justify the decisions made in the design. There is a lack of time, space and experiments systemizing the process.

From the lecturers point of view, Chen et al (2007) [3] consider that it is also important for the teachers to reflect about their own process of teaching, how they guide the students in the studio and how they incite a reflective attitude by the students. They identify three kinds of behaviour in design guiding: imparting, interacting and reflecting and mention that " most of the time in guiding, the behaviour relates to interaction and reflection." [3]

The technologies of information and communication offer a great possibility, in the educational context, of broadening time and space available for the establishment of collaborative moments with interactions between teacher/student and student/student. Learning processes mediated by these technologies demand the register of the discourses thus promoting a systematization and reflection about them. Virtual learning environments 
incorporate these technologies for their specific use in education enabling to register the teaching/learning process as it develops.

It is considered that the use of a virtual learning environment in architectural design courses could contribute to make the design process more transparent as well as the process of teaching/learning architectural design, making it possible to identify the methods used by the students and when and how the teacher intervenes. This registered data could also make it possible for the teachers to evaluate their approach to teaching, allowing them to review how they guide the students into learning and improving their own methods.

Thus, this research seeks to use a virtual learning environment to observe it's validation in an architectural design course, especially observing the possibility of intensifying the moments of interaction and reflection about the design action and the design educational action, as well as point out possible ways to improve the virtual environment used and set guideline for the use of the virtual learning environment in architectural design courses.

\section{Architectural design teaching/learning context}

In this session the traditional development of the architectural design course considered for the experiment is described. The kind of interaction between teacher/student and the kind of documents which register and characterize the teaching/learning process were identified.

The course selected for the experiment was Architectural Design III from the Federal University of Santa Catarina. This course was chosen for being an architectural design course which used the traditional method described above and mainly due to the disposition of the responsible teacher for taking part in the experiment. The main object of study in this course is architectural design of public spaces as an element to configure urban centralities.

This course presents a context very similar to that described by Schön (2000) in which the students learn mainly by doing. It is divided in three main stages, in the first stage the object of study is introduced and the problematic of urban centralities and the use of public spaces are identified.

In this first stage the class is divided in four groups, each group chooses an area for the future development of the design and proposes a theme for the design in that area. Each group hands in a written document as well as drawings explaining their final proposal. At the end of this stage the area for the development of the design and the theme to be used by all the students is elected from among the proposals.

In the second stage the conceptual formulation of the architectural proposal is carried out and the development of an overall urban plan to organize the public space in the urban centrality chosen in the previous stage. For this stage the class is divided into three groups. Initially each group develops a different activity, developing a physical model of the terrain and surrounding area, a digital model of the area and a digital view of the area. 
Following this, each group develops a proposal to relate the chosen place with it's surrounding area, including a volume study for the terrain, the students hand in drawings, plans and a mock up model of their final proposal.

In the third stage each student develops individually their design for the place chosen, they hand in at the end the plans, drawings and, if they wish, a physical model of their design. The collaborative processes in the architectural design courses are intense between teacher/student in the moments of individual orientation, in which the architectural discussion takes place based on the visual-graphic language. Furthermost, all the examples used as reference, sketches and even the final presentation of the design all depend on this language.

However, it is not always possible to establish collaborative processes between student/student, most of the time due to a lack of time in the classes to talk individually to each student and still establish overall discussions with the class about each of the designs being developed.

Certainly, the group discussion about each one of the designs could promote the students to contribute with ideas for the improvement of the designs, elevating the level of the designs. Furthermost, this practice of discussion about the design contributes for the practice of team work which will be important for the students in their professional lives.

Thus, a virtual learning environment, in order to support architectural design courses should, apart from offering tools that support the use of the graphic language, bring forward the promotion of discussions during the whole development of the design.

\section{The experiment}

In this session, initially, the technological resources are specified, such as characteristics of the laboratory available and of the virtual learning environment. Following this, the experiment of using the virtual learning environment in an architectural design course is described.

\section{I Technological resources used}

The virtual learning environment used was AVA-AD (Virtual Learning Environment on Architecture and Design) (avaad.ufsc.br) which is being developed in the Laboratory of Virtual Learning Environments (Hiperlab), in the Federal University of Santa Catarina. This virtual learning environment has the objective of structuring learning situations specifically for knowledge areas which use the visual-graphic language such as architecture and design. Among the tools available in AVA-AD the following stand out: chat, email, forum, instant messages, shared white board (collaborative 2D environment), shared VRML navigation (collaborative 3D environment), shared text editor, document sharing, registration of users and group creation, shared schedule. AVA-AD is based on the Moodle system (moodle.org).

The use of the virtual environment by the students was not mandatory 
since some students only had access to computers and the virtual learning environment at the university and the laboratory available for the architectural design activities presented outdated computers and a slow connection to the internet. These characteristics made it impossible to install some plug-ins, such as Cortona VRML Client, needed for the correct use of some of the tools in the virtual environment such as the collaborative $2 \mathrm{D}$ and $3 \mathrm{D}$ environments.

\subsection{Development of the experiment}

For each stage of the course, described above, the use of specific tools of the virtual learning environment were proposed, selected from the observation of the kind of interaction and document sharing which occurred in the traditional classes.

For the first stage, two forums were created for discussions such as the one in Figure I. The first forum was meant to be used throughout the semester with the objective of clarifying doubts about the use of the learning environment itself. The second forum was created to establish a discussion about the concepts and design methods used in each one of the proposals presented by the students, establishing a reflection about it. This forum is characterized as an open space for orientations and interaction among students.

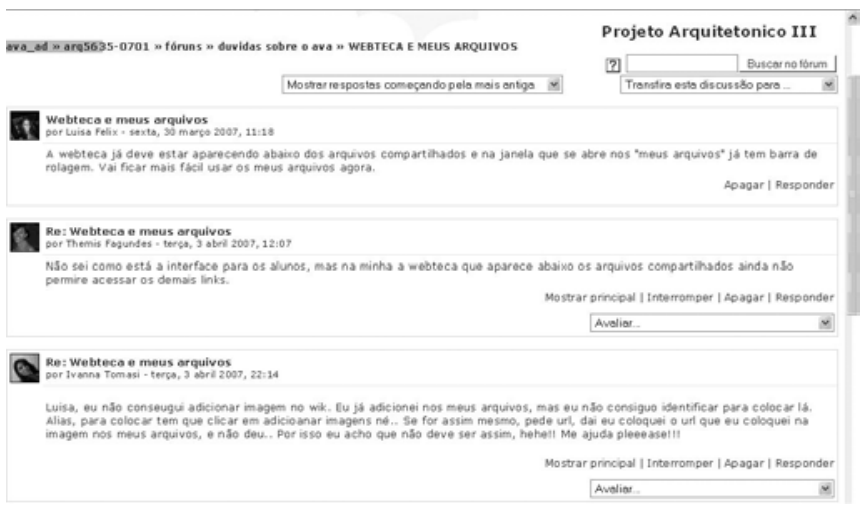

Figure I. Example of discussion in a fórum.

For the development of the idea contest, which is still part of the first stage, a wiki (shared text editor) was created. The proposal was for each group to develop their idea for the location and theme using this tool, an example of wiki can be seen in Figure 2.

At the end of the first stage all the students should analyze the ideas of all the groups, for this a new forum was created for the discussion of the different ideas. Finally, two opinion researches were created: one to elect the location for the design and the other to select the theme which everyone would work on. Figure 3 shows the voting screen in AVA-AD and Figure 4 shows how the results are visualized. 
Figure 2. example of wiki (shared text editor)

Figure 3. Voting interface.

Figure 4. visualization of opinion results.
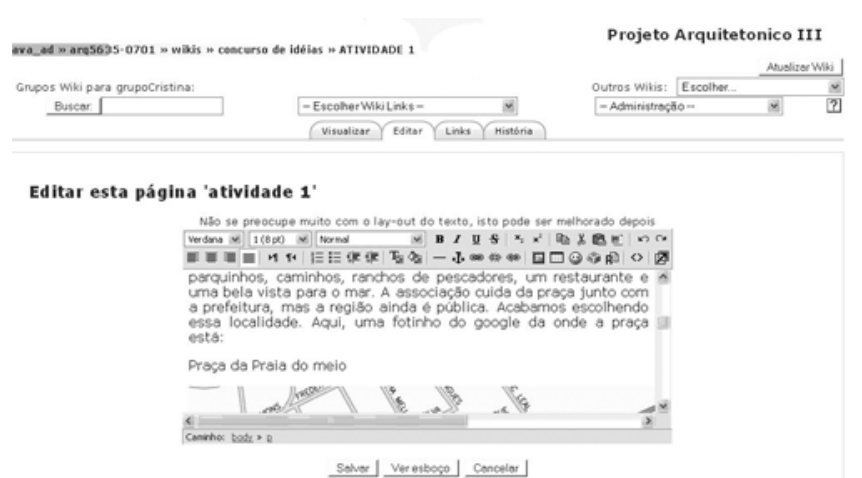

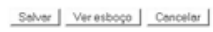
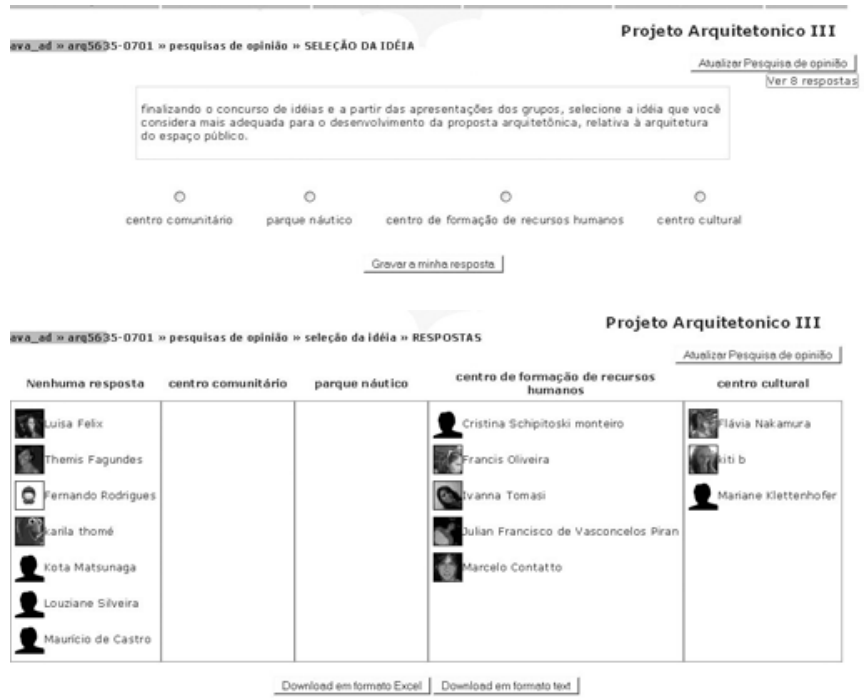

For the second stage al the digital material produced by the groups was made available to everyone in AVA-AD. From the digital model of the location a VRML file was created using 3Dstudio Max, it was made available in the collaborative 3D environment of AVA-AD, for the visualization of the existing volumes around the terrain.

In this stage a wiki was also created for the development of the urban proposal of each group and two forums: one for the discussion about the area and it's characteristics and the other for the discussion about the theme chosen for the design.

In the third stage each student developed a three-dimensional digital model of their design, for this task the students could use whichever software they preferred but most used Google Sketchup or 3Dstudio Max. These models were inserted in the model of the area created in stage 2. From each of these a VRML file was created so that the model could be used in the collaborative 3D environment, two of these environments can be seen in Figure 5. 


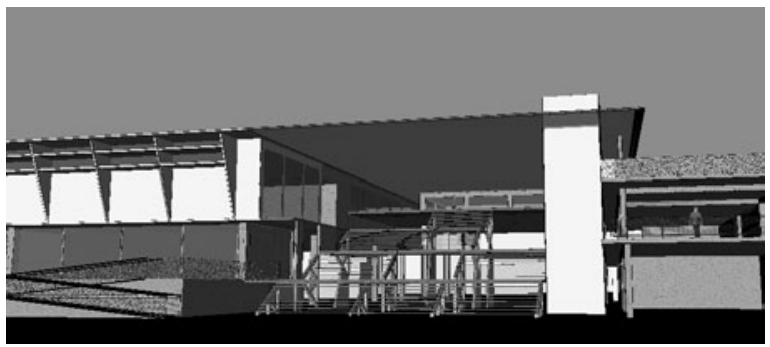

Figure 5. students' designs in the collaborative $3 \mathrm{~d}$ environment

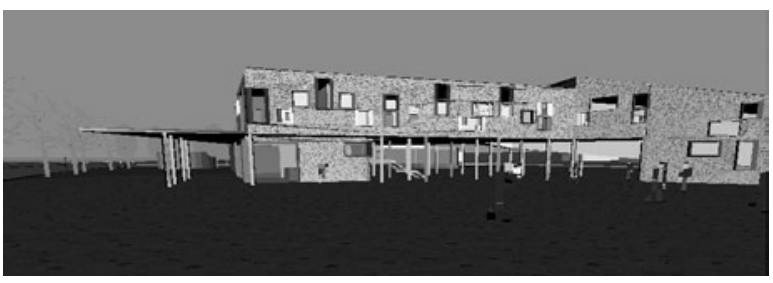

All the students could access the designs of the other and circulate simultaneously while talking in the chat space.

It is important to point out that the schedule for the semester was available in the initial page of the course in AVA-AD, all the material and discussion of previous weeks and all the tasks that the groups had completed could be seen by all the students, it was also possible to see the dates of future deadlines and tasks. Another aspect which is important to point out is that each participant of the course had a space in AVA-AD for keeping their files; these could be shared with any other participant that they chose, making the exchange of documents a lot easier.

It was observed that the use of the collaborative 2D and 3D environments was limited due to the difficulty to insert graphic material in these environments since the material had first to be sent to the administrator of AVA-AD so that he could make it available online.

At the end of the semester the students answered a questionnaire about the use of AVA-AD in the course of architectural design III. The teacher responsible for the course was also interviewed with the purpose of incrementing the data to evaluate the results of the experiment.

\subsection{Results and discussion}

In this session the results of the experiment are presented. The students' answers to the questionnaire, the interview with the teacher, all the material stored in AVA-AD, observations and data collected talking to the participants throughout the semester were all considered for the analysis.

Regarding the overall participation in AVA-AD it was observed that $46 \%$ of the students (six students) took part in less than $50 \%$ of the activities, $38 \%$ (five students) took part in $50 \%$ to $70 \%$ of the activities and only $16 \%$ of the students (two students) took part in more than $70 \%$ of the activities in AVAAD. However, it is important to observe that $54 \%$ of the students (seven 
students) took part in more than $50 \%$ of the activities. The lowest participation was in the third stage when they were developing their designs individually.

It was observed that the difficulty to insert graphic material in the collaborative 2D and 3D environments was one of the main aspects that took the students not to want to use these environments to carry out collaborative activities in these environments, since when their graphic representations and models were finally made available by the administrator, the students had already advanced on the design and the material in the collaborative environment was out of date.

However, the students pointed out the following aspects as a contribution of AVA-AD to the course: the possibility to view the schedule of the course, what had been done and what was still to do; the communication which was made easier through AVA-AD and also the file sharing; the possibility to view what the other were doing and the possibility to go back on the discussions and material stored throughout the semester.

Furthermost, all the designs could benefit from the discussions carried out in the forums about the individual designs in which everyone could take part.

Martens and Achten (2008)[4] examined the advantages and disadvantages of Moodle and say that a virtual environment could replace only partially all that is necessary in a design studio but that a virtual learning environment "makes it possible to maintain live 'in between' critics in the studio" [4]. This commentary agrees with what was considered by the teacher of the course. However, she considered this very important and one of the main contributions of AVA-AD since it reflected directly in the design solutions.

The teacher pointed out that the final design of those students that took part in the activities in AVA-AD more actively, $23 \%$ of the students (three students), was better than the designs of the students that didn't take part in most activities in AVA-AD such as forums. In the teacher's evaluation the design solution presented by these students that took part in most activities were in a higher level compared to the others, she points out that these students explored more options deepening their proposal.

This result is quite different from situations in which the students have to learn web language in order to make their designs understood through the web such as in the study presented by Elger and Russell (2000)[5], in which the students were required to make a presentation of their design available on the world wide web through the use of HTML, JavaScript, Applets, Shockwave and Flash. The authors mention that this has "led to the neglect, in many cases, of the architectural problem itself". [5] They say that in some cases the students concentrate very hard on the presentation "which led to beautifully presented but rather thin design solutions".[5]. Therefore the use of environments in which the students don't need to understand the web language in order to expose their ideas through the web eliminates this problem and even leads to richer designs as shown in this case. 
The commentaries made by Pallof and Pratt (2002)[6] make it possible to understand the consideration made by the teacher.These authors point to the possibility of thinking more in the discussions through the forums since the commentaries in a forum can be made when the student desires, giving them time to think more about what their are doing. This allows more reflection and commitment to what they are doing when compared to a live discussion. This is also valid for the teacher who has more time to reflect before answering the student's questions; this reflection is both on how to solve the problem and how to answer in order to incite a reflective attitude on the student making them find the solution to the problem. Even in real time discussions, through a chat tool for example, the written expression could demand more reflection. Moreover, the collaborative 3D environment allowed participants in different places to view and walk through the spaces simultaneously while discussion in the chat space allowing them to advance even more in their designs between one class and the next, solving several aspects in a distance manner.

From this experiment it was possible to propose changes to the virtual environment AVA-AD and also make some suggestions regarding the way the environment could be used to reach the best of its potential. One of the most important changes in the virtual environment regards the way graphic material is inserted in the collaborative 2D and 3D environments. Both images and 3D models should be inserted directly from the student's computer into the collaborative environment in order to have the material up to date when they wish to use these environments. Furthermost, the 3D collaborative environment should allow students to insert other models in the same scene, that way they wouldn't have to upload the whole model for the scene again in order to add a small detail.

Another aspect that could be improved in the environment is the orientation in the course space. As it is now, the student can get to the same place in the environment using several different paths. This can be confusing, causing the students to wonder if a determined task or forum is the same one they have already visited or a different one. It is considered that a course map could solve this problem. This course map is similar to a site map and in this case there would be a different map for each course showing only what matters to that course and not the whole structure of AVA-AD. Another change that could make the navigation easier for the students is to highlight the tasks which the student had already completed, which doesn't mean that they can't go back on that task.

Regarding the way the virtual environment is used it is recommended to carry out a demonstration of the environment in the beginning of the course, showing the students how to access the course space and how to use the environment and its tools. This could help avoid navigation problems by the students. Another suggestion is to create a forum exclusively to discuss issues about the environment itself. 
It is considered that establishing a minimum of weekly participation by the students or a minimum of participation per activity such as forums guarantees that everyone will take part in the discussions leading to higher level in the discussions and therefore in the designs

In order to make the navigation easier by the students it is suggested that the course should be divided in stages and only one forum should be created per stage of the course in the virtual environment instead of dividing by weeks, that way there would be no confusion as to in which forum a question should be posted for example. However, a weekly calendar should still be available to make it possible for the students to view what they have already done and what is still to do as well as deadlines.

\section{Conclusions}

The experiment described demonstrates the possibility of transposing to the virtual environment AVA-AD several aspects of the dynamic of the architectural design course analyzed, pointing to several improvements on the quality of interaction between teacher/student and between students.

Several problems were identified, such as lack of appropriate laboratories for the students' use which limited the participation to those students who had a computer and internet access at home and the difficulty to insert graphic material in the virtual learning environment which depended on the administrator. It is considered that these problems can be solved through a technological approach (improving the virtual environment) and economic approach (improving the laboratories).

In a pedagogical aspect, the experiment demonstrates the possibility of establishing teaching/learning processes of design in the environment. The discussions are now registered and visible in the environment allowing all the students to question and analyze the designs of the others making the designs richer. This is different to the situation before in which the discussions happened individually between each student and the teacher.

It was observed that the collaborative $2 D$ and $3 D$ environments have a great potential to improve even more this kind of course, however, in this experiment they did not achieve this potential due to the difficulty to insert graphic material in these environments.

It is considered that one of the main contributions of the use of a virtual environment in architectural design courses is the possibility to register the whole process, making the discussions explicit and making it possible to view the interventions made by the teacher in each design. The teacher now has registered data of how she establishes the discussions and incites the reflection on the students, this allows her to review her own teaching strategy and improve it. It allows the teacher to observe what kind of discussion and material she used with certain students, leading to a good design and what kind of discussion and materials she used with other students which did not work, leading to a design that was not so good in some cases. It is also 
possible to observe where she failed to guide these students and what should be improved. Moreover, the discussions were broadened to the whole group of students, so everyone could benefit from a commentary made about one individual design, or from a question answered to one student, as well as making it possible for the students to help each other and therefore reflect more about the design process itself.

From these registered data it is possible to develop studies to identify the structures of knowledge which support the education on architectural design and observe in which moments these elements of knowledge are introduced as the students show difficulty throughout the course, contributing, thus, to the systematization of teaching/learning processes on architectural design.

\section{References}

I. SILVA, Elvan. Uma introdução ao projeto arquitetônico. Porto Alegre: Ed. da Universidade, UFRGS, 1984.

2. SCHÖN, Donald. Educando o profissional reflexivo: um novo design para o ensino e a aprendizagem. Porto Alegre:Artmed, 2000.

3. CHEN, Jiun-De et. al. Minding the mind in design tutoring and guiding. Sydney: University of New South Wales, 2007.

4. MARTENS, Bob; ACHTEN, Henri. Do you Moodle? Antwerpen:Architecture in Computro [26th eCAADe Conference Proceedings], 2008.

5. ELGER, Dietrich and RUSSELL, Peter. Using the World Wide Web as a Communication and Presentation Forum for Students of Architecture. Weimar: Promise and Reality: State of the Art versus State of Practice in Computing for the Design and Planning Process [18th eCAADe Conference Proceedings], 2000.

6. PALLOFF, Renan M. \& PRATT, Keith. Construindo comunidades de aprendizagem no ciberespaço: estratégias eficientes para salas de aula on-line. Porto Alegre:Artmed, 2002.

Luisa Dalla Vecchia', Adriane da Silva ${ }^{2}$ and Alice Pereira ${ }^{3}$

'Universidade do Oeste de Santa Catarina, Brazil, ${ }^{2}$ Universidade Federal de

Pelotas, Brazil, ${ }^{3}$ Universidade Federal de Santa Catarina, Brazil

Iisa_luls@hotmail.com, 2adribord@hotmail.com, ${ }^{3}$ acybis@gmail.com 